\title{
IN Silico approach of some selected honey constituents as SARS-CoV-2 main protease (COVID-19) inhibitors
}

\author{
Heba E. Hashem \\ Department of Chemistry, Faculty of Women, Ain Shams University, Heliopolis, 11457, Cairo, Egypt. \\ hebahashem89@yahoo.com,
}

\section{Abstract:}

The huge attack of coronavirus disease 2019 (COVID-19) over all the world forces the researcher around the world to study the crystal structure of the main protease $\mathrm{M}^{\text {pro }}$ ( 3-chymotrypsin-like cysteine enzyme) which is the essential enzyme for coronavirus processing the polyproteins and its life cycles. And by the way, the inhibition of this enzyme active site becomes the target of all scientists of drug discovery in order to overcome this disease. In this study, we have used the molecular modeling approach to evaluate the activity of different active compounds from honeybee and propolis to inhibit the presented sars-cov-2 main protease via Schrödinger Maestro v10.1. the presented study resulted in six main compounds possess high binding energy with the receptor active site of COVID-19 main protease. we hope this study being the way for honeybee constitution as an effective ligand for sars-cov-2 main protease inhibition and be in the medicinal study of antiCOVID-19 therapeutic drugs.

Keywords: SARS-CoV-2, honeybee, propolis, Molecular docking, Structure activity relationship (SAR), $\mathrm{M}^{\text {pro }}$ inhibition.

\section{Introduction:}

The crystal structure of coronavirus COVID-19 main protease was studied by medicinal chemists around all the world to develop antiviral drugs. It was mentioned that the COVID-19 doesn't produce many proteins and by the way, there are not many targets for coronavirus inhibition. The threedimensional structure of coronavirus main protease is like that of SARS-CoV $M^{\text {pro }}$, its RNA genome is about $82 \%$ like SARS-CoV which belongs to the betacoronavirus genus [1,2]. The COVID-19 has been named SARS-CoV-2 and its drug target is $M^{\text {pro }}$ (3-chymotrypsin-like cysteine enzyme) which is the essential enzyme for coronavirus processing the polyproteins [3-5].

$M^{\text {pro }}$ yields about $790 \mathrm{kDa}$ polypeptide at different 11 spots of the large polyprotein which is the key to viral reproduction [6]. The inhibition of these active sites of the enzyme is the target point 
for producing anti-COVID-19 drugs. But due to there is no known cleavage specificity of similar human proteases, unlikely the inhibitors may be toxic [7].

Natural products play an attractive role in the production of drugs for several diseases without harmful side effects [8]. Bee's productions have been used in medicine for several diseases included tumor treatment and immune-related diseases [9,10]. Especially, honey and propolis produced by bees have been possessed several biological activities like anti-inflammatory, antibiotic, antifungal, antiviral, antioxidant, anti-cancer, and immunomodulatory, hepatoprotective effects [11-13].

General composition of propolis is about $50 \%$ resins, $30 \%$ waxes, $10 \%$ essential oils, $5 \%$ pollen, and 5\% of various organic compounds included polyphenols and flavonoids, and more than 200 constituents have been elucidated [14-17]. Honey is the main bee's production from different plant and so the chemical composition of honey depends mainly on the source and environment of the plant which reflected on its biological activity. The dark honey, Manuka Honey, has attracted attention for its biological properties, especially as an anti-viral effect. Several studies have been shown that there are many flavonoids and polyphenolic compounds in Manuka honey constituent [18-21] which suggested being accountable to its anti-microbial, anti-viral, and antioxidant effects [22-25].

According to the great biological effect of honeybee and propolis, in the presented study six selected compounds which have previous attention on their biological effect [23, 26] namely, 3-phenyllactic acid, caffeic acid phenethyl ester (CAPE), lumichrome, Galangin, chrysin, and caffeic acid used to study their potent anti-COVID-19 effect in silico approach (molecular docking), hoping this study being the way for honeybee constitution as an effective anti-COVID-19 drugs.

\section{Material and Methods:}

\section{Preparation of honeybee's chemical compounds (Ligand):}

The 2D structure of the six selected chemical compounds of honeybee and propolis were obtained in the SDF format from PubChem database. They were subjected to LigPrep module of Schrodinger Maestro v10.1, and converted to three-dimensional 3D structure by including ionization, variation, stereochemical, correction, and energy minimization and optimization of geometry. Minimization using Optimized Potentials for Liquid Simulation-2005 force field (OPLS_2005). Ionization state were carried out at PH 7.0 +/- 2.0 using Epik module. Generating tautomer, desalted, varying their other chiral center, and a single low energy ring confirmation per ligands. The optimized ligands 
were then used for docking. The 2D structure of selected compounds and their PubChem CID are shown in Fig 1.

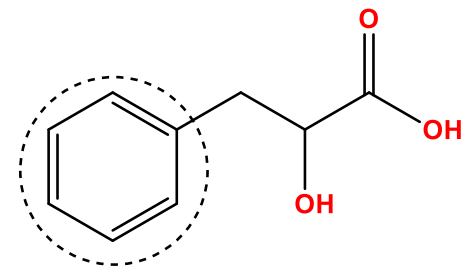

3-Phenyllactic acid Pubchem CID: 3848<smiles>O=C(O)/C=C/c1ccc(O)cc1O</smiles>

Caffeic acid Pubchem CID: 689043<smiles>O=c1c(O)c(I)oc2cc(O)cc(O)c12</smiles>

Galangin PubChem CID: 5281616<smiles>O=C(/C=C/c1ccccc1)OCCc1ccccc1O</smiles>

Caffeic acid phenylethyl ester PubChem CID: 5281787<smiles>O=c1cc(-c2ccccc2)oc2cc(O)cc(O)c12</smiles>

Chrysin

Pubchem CID:5281607<smiles></smiles>

Lumichrome PubChem CID: 5326566

Figure 1: Two dimensional $2 D$ structures of six selected honeybee chemical compounds

\section{COVID-19 main protease Identification and Preparation:}

The three dimensional crystal structure of COVID-19 main protease in complex with $\mathrm{N}-(2-$ phenylethyl)methanesulfonamide (PDB ID: 5R7Y) was downloaded from the protein data bank (https://www.rcsb.org) in $1.65 \mathrm{~A}^{\circ}$ resolution. Protein structure was refined by assigning their bond orders, adding their missing hydrogen atoms and disulfide bonds and removing water molecules within $5 \mathrm{~A}^{\mathrm{o}}$ of the heteroatom. Optimizing the side-chain hydroxyl groups Asn, Gln, and His states using OPLS_2005 force field. Restrained minimization of the input protein coordinates by $0.3 \mathrm{~A}^{\mathrm{o}}$ RMSD (Root Mean Square Deviation). 


\section{Receptor Grid Generation:}

The interaction between different prepared ligand and receptor protein was studied by setting up the receptor grid generation. The already bound ligand was excluded from the grid generation and the site of docked ligand is confined to the enclosing box, centroid of docked pose and in similar size to the workspace ligand.

\section{Molecular Docking (Glide Docking):}

The prepared ligands and protein were docked using Schrödinger maestro software v10.1. using SP flexible ligand mode, with 10 possess per ligand. Energy minimized possess were performed with final scoring using Glide score, the lowest glide scores (the best docked pose) for each ligand were recorded, as well as, the RMSD value (root mean square deviation) between the observed X-ray crystallographic of protein (native structure) and the predicted confirmation of input ligand geometry were computed. The 3D structures of the docked protein and the binding interaction distance of each ligands with the receptor were analyzed using PyMOL software.

\section{$\underline{\text { Results and Discussion: }}$}

According to the several reported studies on some of honeybee constitutions as antiviral compounds [23-27], and a survival need of an effective ant-covid-19 drugs without harmful side effect, the presented study directed to computational drug discovery.

Docking simulation studies of the six selected honeybee constitution to the covid-19 main protease using the advanced molecular docking program (Schrödinger maestro v10.1) revealed very interesting results. The details of all docking score, glide score, potential energy, and RMSD for the ligands (1-6) to the selected protein is summarized in table 1. It was shown that all ligands have good binding affinity towards the receptor in different ways. Compounds 2,4,5 have more glide score arising from electrostatic attraction as well as more than one hydrogen bond between hydroxyl groups of ligand and different amino acid residues. The most binding modes affinity of ligands 1-6 with the receptor are shown in figure 2. 
Table 1: Docking results for ligands 1-6 with COVID-19 main protease:

\begin{tabular}{|c|c|c|c|c|c|}
\hline Number & Ligands & $\begin{array}{c}\text { Potential } \\
\text { energy }\end{array}$ & $\begin{array}{c}\text { Docking } \\
\text { Score }\end{array}$ & $\begin{array}{c}\text { Glide } \\
\text { score }\end{array}$ & RMSD \\
\hline $\mathbf{1}$ & 3-phenyllactic acid & 34.546 & -5.867 & -5.868 & 0.049 \\
\hline $\mathbf{2}$ & $\begin{array}{c}\text { Caffeic acid phenylethyl } \\
\text { ester (CAPE) }\end{array}$ & 46.07 & -6.383 & -6.386 & 0.048 \\
\hline $\mathbf{3}$ & Caffeic acid & 14.22 & -4.387 & -4.387 & 0.035 \\
\hline $\mathbf{4}$ & Chrysin & 63.126 & -6.097 & -6.103 & 0.047 \\
\hline $\mathbf{5}$ & Galangin & 74.258 & -6.295 & -6.307 & 0.044 \\
\hline $\mathbf{6}$ & Lumichrome & 94.141 & -5.205 & -5.205 & 0.040 \\
\hline
\end{tabular}

$C A P E$ residue was stabilized within the receptor by interacting through electrostatic (bi-bi stacking) of phenyl ring with aromatic ring of (HIE-41) of the receptor with $4.2 \mathrm{~A}^{\mathrm{o}}$, while the other closing residues of amino acid (THR-24) and (THR-26) are having strong hydrogen bond with the two hydroxyl group of CAPE ligand (cf. Fig.2).

Chrysin is binding with (SER-46), (THR-24), and (THR-26) through hydrogen bond with 2.4, 2.6, $2.1 \mathrm{~A}^{\mathrm{o}}$, respectively, beside strong electrostatic (bi-bi stacking) interaction of phenyl ring with (HIE41) with $3.8 \mathrm{~A}^{\mathrm{o}}$.

Galangin interacted with the receptor with glide score $-6.307 \mathrm{Kcal} / \mathrm{mol}$ through hydrogen bond with two amino acid residues (SER-46), (THR-24), as well as other bi-bi interaction with (HIE-41). In the other way, caffeic acid interacted with high affinity with COVID-19 main protease by binding its hydroxyl groups with two amino acid residues ((GLN-189), (HIE-164) of the receptor by hydrogen bond with 2.0, $2.8 \mathrm{~A}^{\mathrm{o}}$, respectively, beside other bi-bi interaction with (HIE-41) with 4.1 $\mathrm{A}^{\mathrm{o}}$ (cf.Fig.2).

The other two ligands Lumichrome and 3-phenyllactic acid posses moderate binding affinity with the receptor with glide score -5.205 and -5.867 Kcal/mol, respectively. Lumichrome and 3phenyllactic acid binding within the pocket through bi-bi stacking with (HIE-41), while 3phenyllactic acid possess also strong hydrogen bond with only one amino acid residue (GLN-189) (cf. Fig. 2).

The three-dimensional crystal graphical structure of the docked six ligand 1-6 with the COVID-19 main protease are presented in Figure 3.

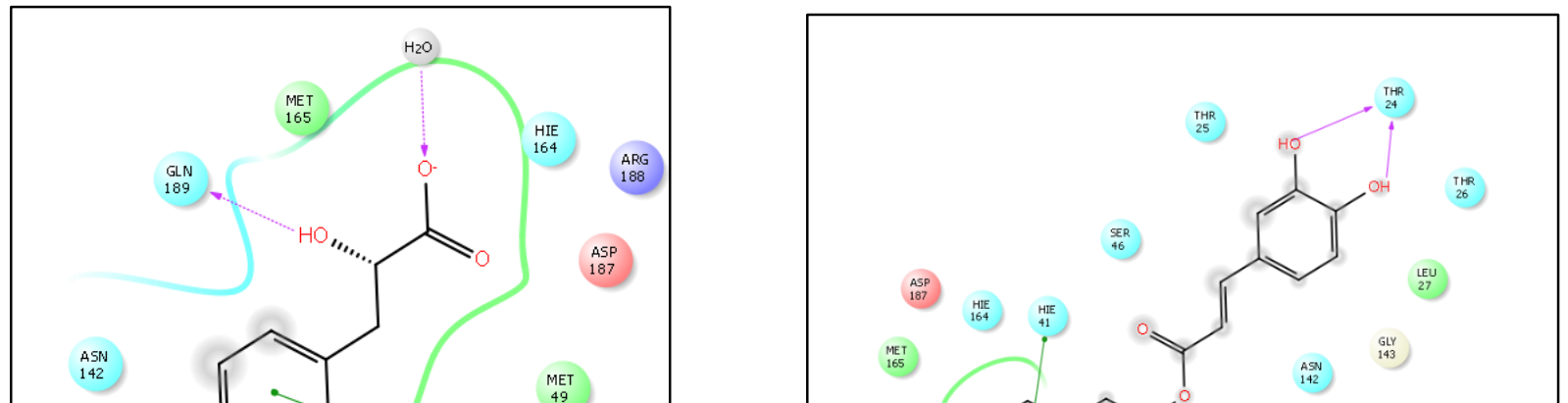


3-phenyllactic acid
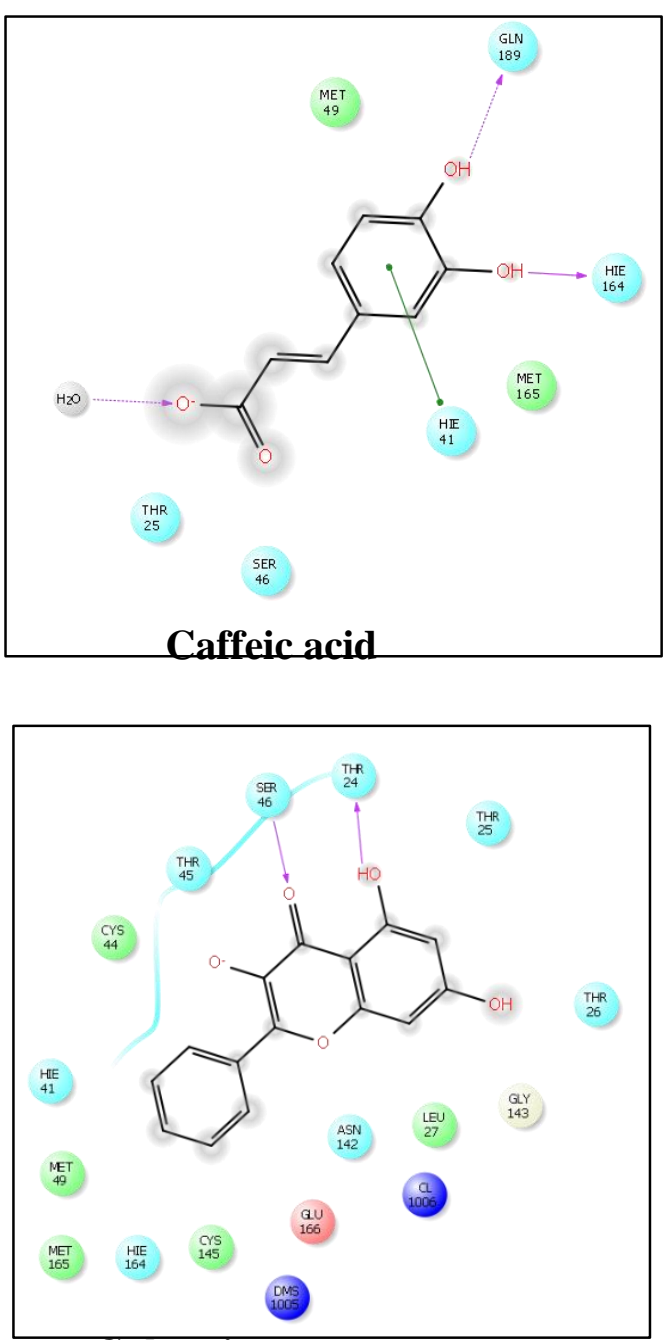

Galangin
Caffeic acid phenylethyl ester CAPE
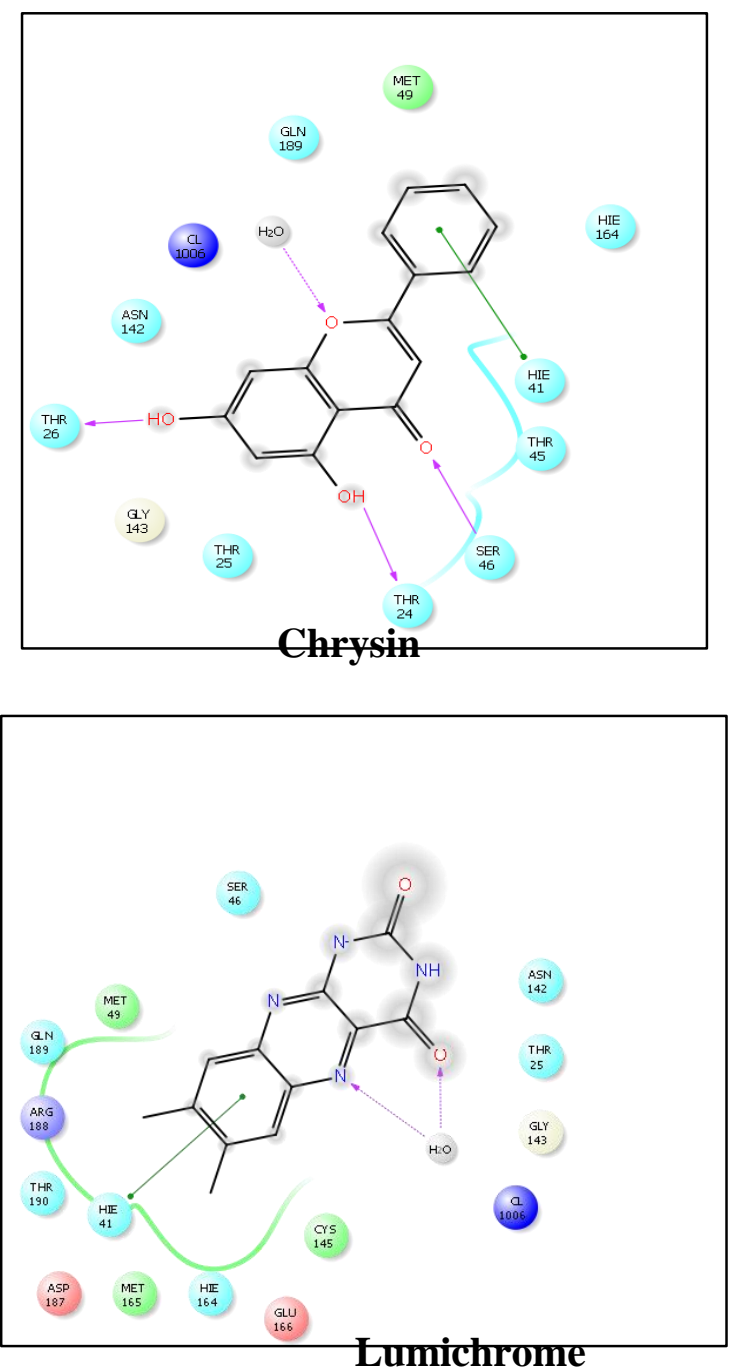

Figure 2: Ligand interaction diagram of six selected honeybee constitutions (1-6) with COVID-19 main protease.

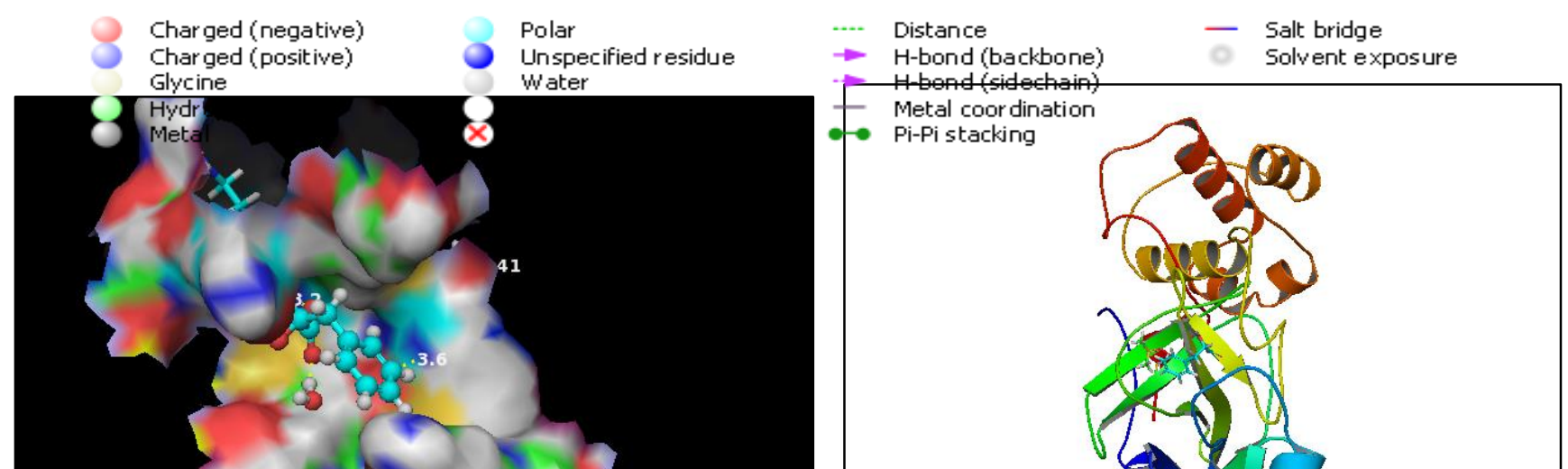


(1A)

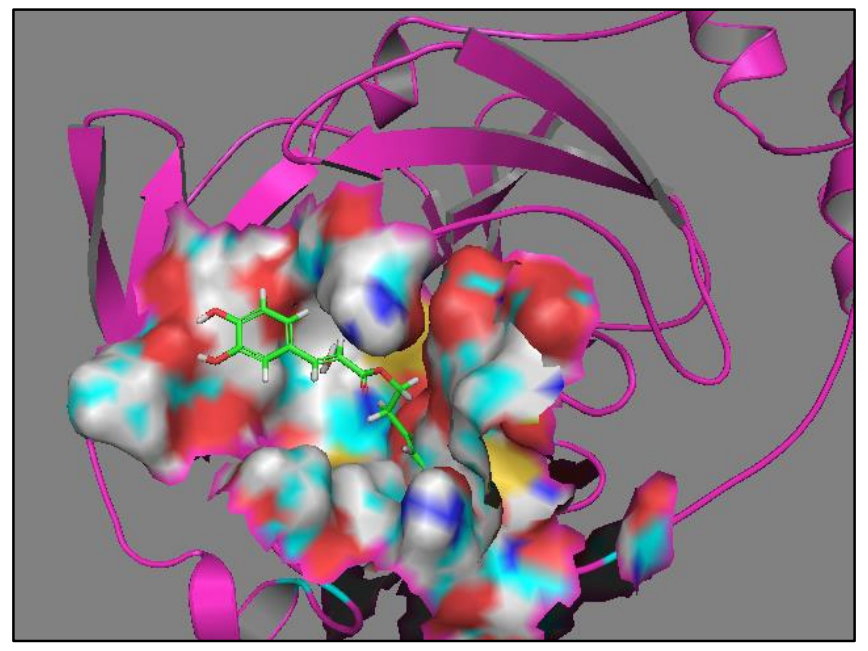

(2A)

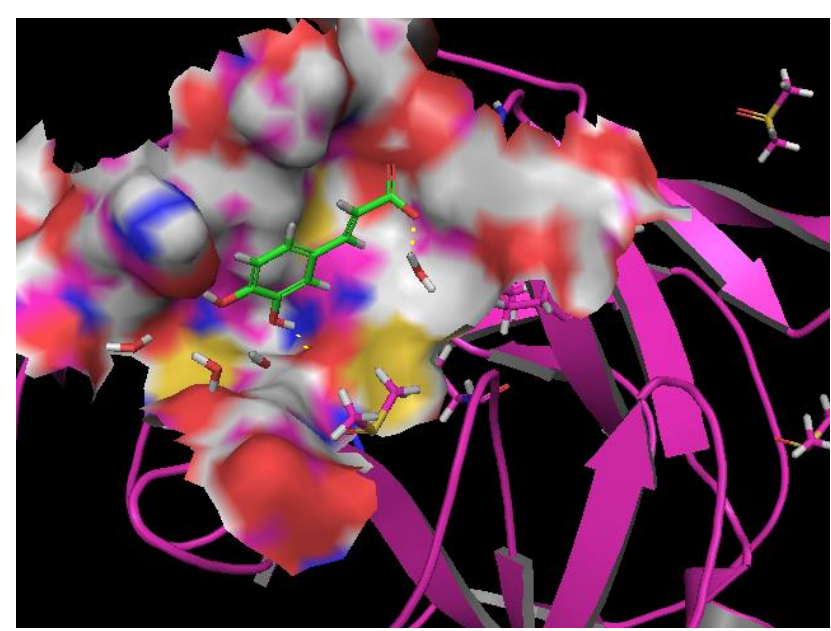

(3A)

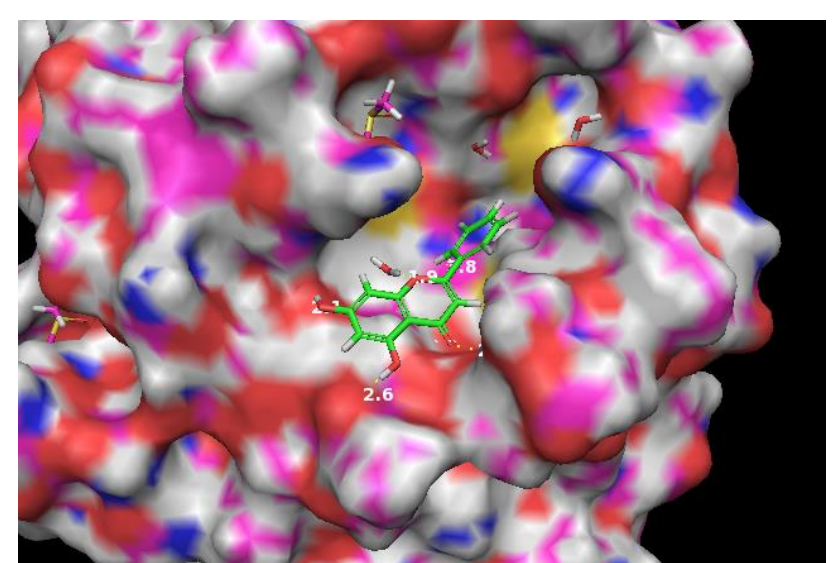

(1B)

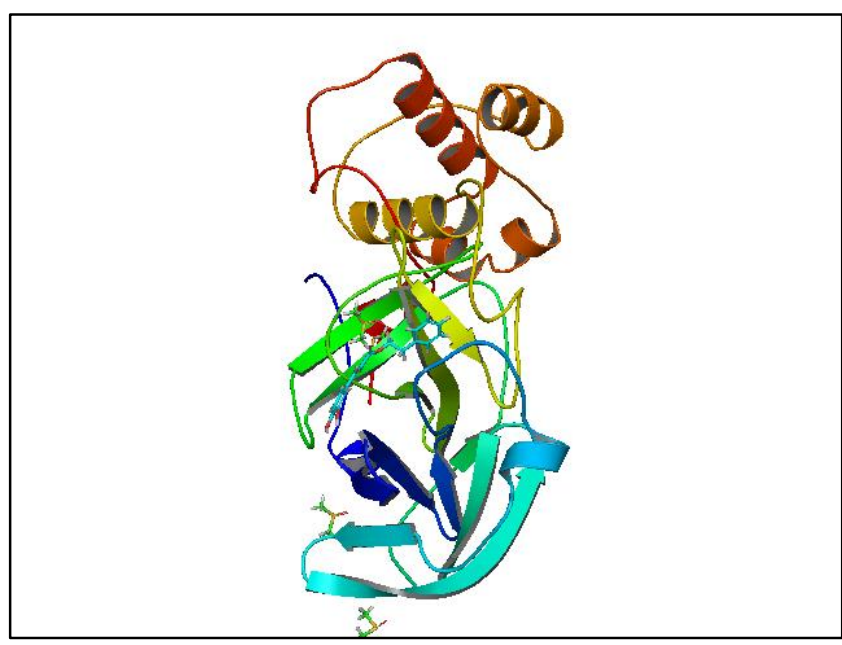

(2B)

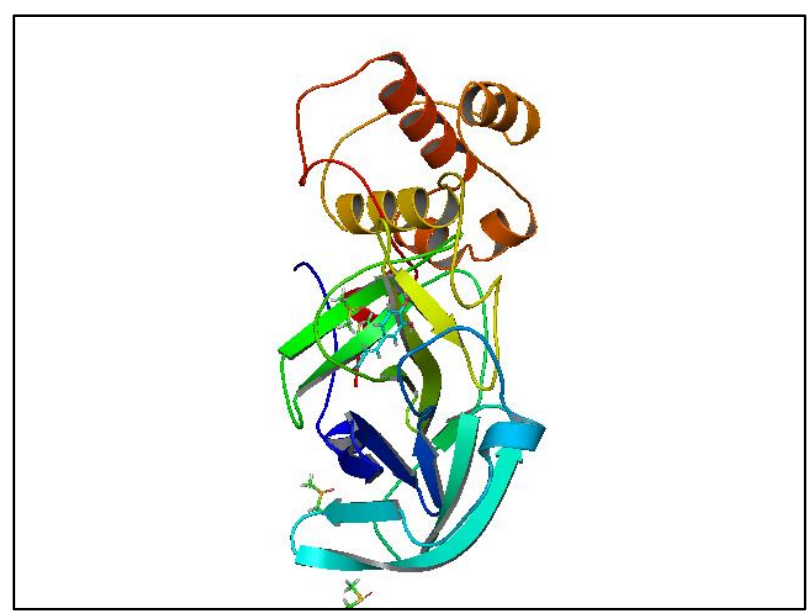

(3B)

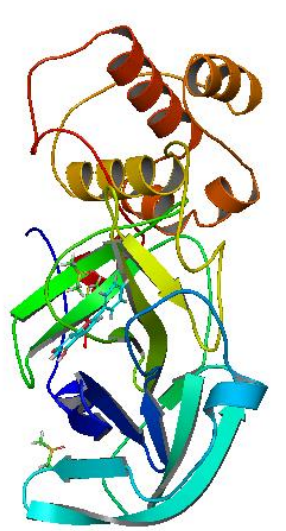


$(4 \mathrm{~A})$

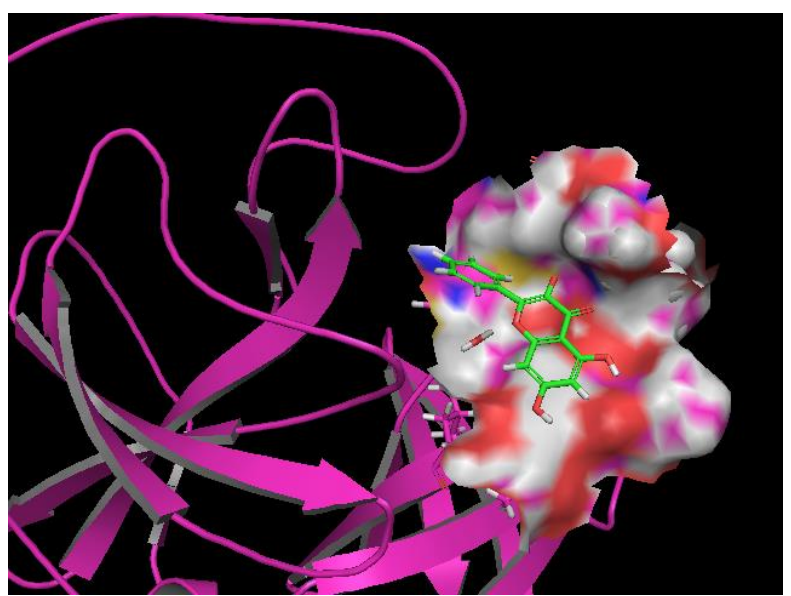

(5A)

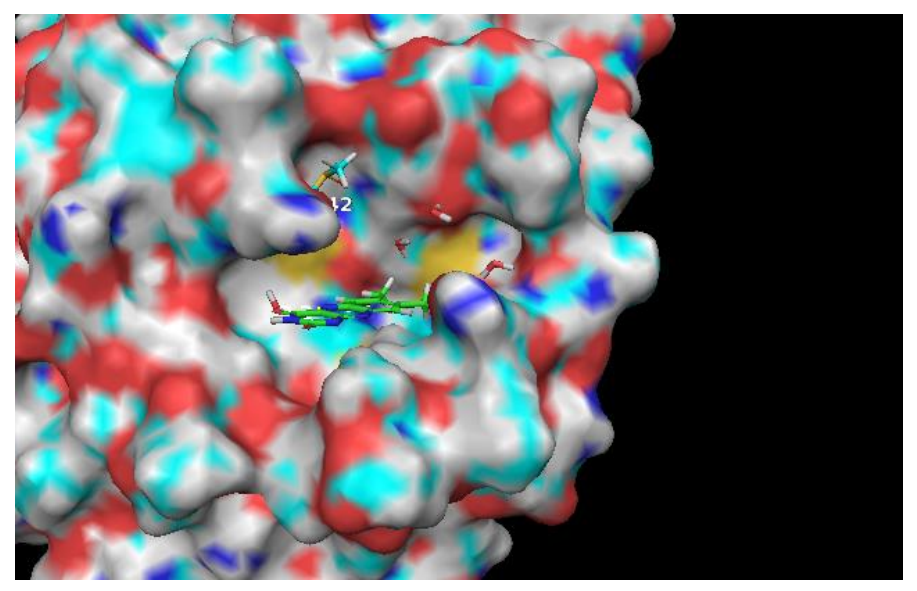

(6A)
(4B)

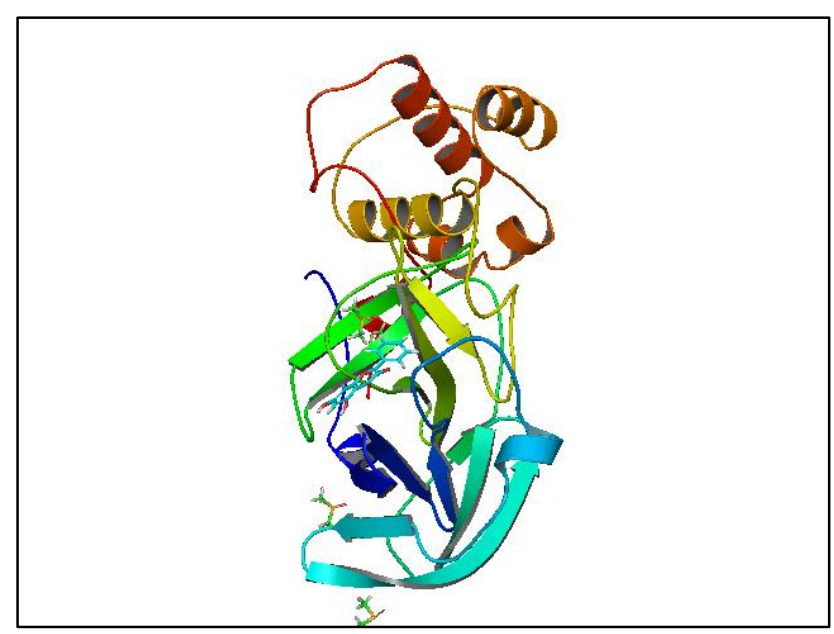

(5B)

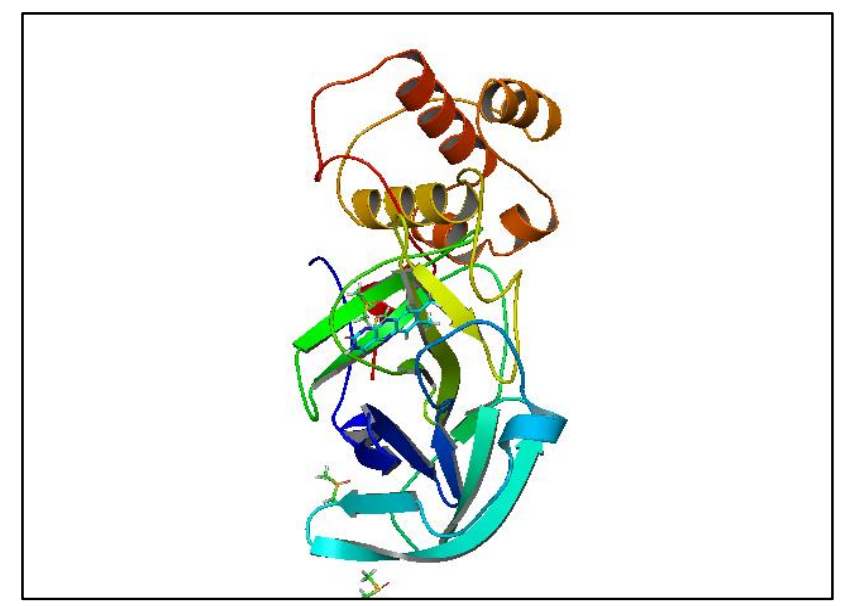

(6B)

Figure 3: (A) Three-dimensional 3D interaction diagrams of ligands 1-6 docked in the active site of COVID-19 protease using PyMOL software; red color reflects the high polar area, blue color reflects the mild polar area and grey color reflects the hydrophobic area. (B) Crystal Structure of COVID-19 main protease in complex with ligands 1-6.

\section{Conclusion:}

Honeybee and propolis include a wide range of flavonoid compounds with several biological activities. The presented study screened in silico the biological activity of six compounds present in 
honeybee and propolis as antiviral components against the COVID-19 main protease. The study revealed that four compounds have strong binding affinity with good glide score and may inhibit the COVID-19 main proteas and virus replication. The study aimed for further in-vivo study in order to produce novel natural anti-COVID-19 drugs without any harmful side effect.

\section{$\underline{\text { Reference: }}$}

1- P. Zhou, X.-L. Yang, X.-G. Wang, B. Hu, L. Zhang, W. Zhang, H.-R. Si, Y. Zhu, B. Li, C.L. Huang, H.-D. Chen,J. Chen, Y. Luo, H. Guo, R.-D. Jiang, M.-Q. Liu, Y. Chen, X.R. Shen, X. Wang, X.-S. Zheng, K. Zhao, Q.-J. Chen,F. Deng, L.-L. Liu, B. Yan, F.X. Zhan, Y.-Y. Wang, G.-F. Xiao, Z.-L. Shi, A pneumonia outbreak associated with a new coronavirus of probable bat origin. Nature 579 (2020) 270-273.

Doi:10.1038/s41586-020-2012-7pmid:32015507

2- F. Wu, S. Zhao,B. Yu,Y.-M. Chen, W. Wang, Z.-G. Song, Y. Hu, Z.-W. Tao, J.-H. Tian, Y.Y. Pei, M.-L. Yuan, Y.-L. Zhang, F.-H. Dai, Y. Liu, Q.-M. Wang, J.-J. Zheng, L. Xu, E. C. Holmes, Y.-Z. Zhang, A new coronavirus associated with human respiratory disease in China. Nature 579 (2020) 265-269. doi:10.1038/s41586-020-2008-3pmid:32015508

3- K. Anand, J. Ziebuhr, P. Wadhwani,J. R. Mesters, R. Hilgenfeld, Coronavirus main proteinase $\left(3 \mathrm{CL}^{\mathrm{pro}}\right.$ ) structure: Basis for design of anti-SARS drugs. Science 300 (2003)1763-1767. doi:10.1126/science.1085658pmid:12746549

4- R. Hilgenfeld, From SARS to MERS: Crystallographic studies on coronaviral proteases enable antiviral drug design. FEBS J. 281 (2014) 4085-4096. doi:10.1111/febs.12936pmid:25039866

5- A. E. Gorbalenya, S. C. Baker, R. S. Baric, R. J. de Groot, C. Drosten, A. A. Gulyaeva, B. L. Haagmans, C.Lauber, A. M. Leontovich, B. W. Neuman, D. Penzar, S. Perlman, L. L. M. Poon, D. Samborskiy, I. A. Sidorov, I.Sola, J. Ziebuhr, Severe acute respiratory syndromerelated coronavirus: The species and its viruses - a statement of the Coronavirus Study Group. Nat. Microbiol. (2020). doi:10.1038/s41564-020-0695-z

6- M. Macchiagodena, M. Pagliai, and P. Procacci, Inhibition of the Main Protease 3CL-proof the Coronavirus Disease 19 via Structure-Based Ligand Design and Molecular

Modeling. arXiv preprint arXiv:2002 (2020) 09937.

7- Linlin Zhang, Daizong Lin, Xinyuanyuan Sun, Ute Curth, Christian Drosten, Lucie Sauerhering, Stephan Becker, Katharina Rox, Rolf Hilgenfeld, Crystal structure of SARSCoV-2 main protease provides a basis for design of improved $\alpha$-ketoamide inhibitors, Science (2020). doi: 10.1126/science.abb3405

8- C.Liu, D. Cai, L. Zhang, W. Tang, R. Yan, H. Guo, X. Chen, Identification of hydrolyzable tannins (punicalagin, punicalin and geraniin) as novel inhibitors of hepatitis B virus covalently closed circular DNA. Antiviral research, 134 (2016) 97-107. doi.org/10.1016/j.antiviral.2016.08.026 
9- W. Więckiewicz, M. Miernik, M. Więckiewicz, T. Morawiec, Does propolis help to maintain oral health?. Evid Based Complement Alternat Med 2013 (2013) 1-8.

doi.org/10.1155/2013/351062

10- N. Yusuf, C. Irby, S.K. Katiyar, C.A. Elmets, Photoprotective effects ofgreen tea polyphenols. Photodermatol, Photoimmunol and Photomed, 23 (2007) 48-56. doi.org/10.1111/j.1600-0781.2007.00262.x

11- M.F. Tolba, S.S. Azab, A.E. Khalifa, S.Z. Abdel-Rahman, A.B. Abdel-Naim, Caffeic acid phenethyl ester, a promising component of propolis with a plethora of biological activities: A review on its anti-inflammatory, neuroprotective, hepatoprotective, and cardioprotective effects. IUBMB Life 65 (2013) 699-709. doi.org/10.1002/iub.1189

12- A. H. Banskota, Y. Tezuka, and S. Kadota, Recent progress in pharmacological research of propolis, Phytotherapy Research, 15 (2001) 561-571. doi.org/10.1002/ptr.1029

13- G. A. Burdock, Review of the biological properties and toxicity of bee propolis (propolis),Food and Chemical Toxicology, 36 (1998) 347-363. doi.org/10.1016/s0278-6915(97)00145-2

14- Y.K. Park, S.M. Alencar, C.L. Aguiar, Botanical origin and chemical composition of Brazilian propolis. J Agric Food Chem. 50 (2002) 2502-2506. doi.org/10.1021/jf011432b

15- J.M. Sforcin, V. Bankova. Propolis: is there a potential for the development of new drugs? J Ethnopharmacol. 133 (2011) 253-260.

doi.org/10.1016/j.jep.2010.10.032

16- S. Patel, Emerging adjuvant therapy for cancer: propolis and its constituents. J Diet Suppl. 13 (2016) 245-268. doi.org/10.3109/19390211.2015.1008614

17- B.M. Hausen, E. Wollenweber, H. Senff, Post B. Propolisallergy. (I). Origin, properties, usage and literature review.Contact Dermatitis. 17 (1987) 163-170. doi.org/10.1111/j.1600-0536.1987.tb02699.x

18- S. Patel, S. Cichello, Manuka honey: An emerging natural food with medicinal use. Nat. Prod. Bioprospect. 3 (2013) 121-128.

doi.org/10.1007/s13659-013-0018-7

19- C.W. Chan, B.J. Deadman, M. Manley-Harris, A.L. Wilkins, D.G. Alber, E. Harry, Analysis of the flavonoid component of bioactive New Zealand manuka (Leptospermum scoparium) honey and the isolation, characterisation and synthesis of an unusual pyrrole. Food Chem. 141 (2013) 1772-1781.

doi.org/10.1016/j.foodchem.2013.04.092 
20- S. Oelschlaegel, M. Gruner, P. Wang, A. Boettcher, I. Koelling-Speer, K. Speer, Classification and characterization of Manuka honeys based on phenolic compounds and methylglyoxal. J. Agric. Food Chem. 60 (2012) 7229-7237.

doi.org/10.1021/jf300888q

21- M.D.Mandal, S. Mandal, Honey: Its medicinal property and antibacterial activity. Asian Pac. J. Trop. Biomed. 1 (2011) 154-160. doi.org/10.1016/s2221-1691(11)60016-6

22- S.A. Sell, P.S. Wolfe, A.J. Spence, I.A. Rodriguez, J.M. McCool, R.L. Petrella, K. Garg, J.J. Ericksen, G.L. Bowlin, A Preliminary study on the potential of manuka honey and platelet-rich plasma in wound healing. Int. J. Biomater. 2012 (2012) 313781. doi:10.1155/2012/313781.

23- V. Tomblin, L.R. Ferguson, D.Y. Han, P.Murray, R. Schlothauer, Potential pathway of anti-inflammatory effect by New Zealand honeys. Int. J. Gen. Med. 7 (2014) 149-158. doi.org/10.2147/ijgm.s45839

24- J. Tonks, E. Dudley, N.G. Porter, J. Parton, J. Brazier, E.L. Smith, A. A. Tonks, 5.8$\mathrm{kDa}$ component of manuka honey stimulates immune cells via TLR4. J. Leukoc. Biol. 82 (2007) 1147-1155. doi.org/10.1189/jlb.1106683

25- H.A. Alzahrani, R. Alsabehi, L. Boukraâ, F. Abdellah, Y. Bellik, B.A. Bakhotmah, Antibacterial and antioxidant potency of floral honeys from different botanical and geographical origins. Molecules 17 (2012) 10540-10549.

doi.org/10.3390/molecules170910540

26- Y. Ishida, R. Gao, N. Shah, P. Bhargava, T. Furune, S.C. Kaul, K. Terao, R. Wadhwa, Anticancer Activity in Honeybee Propolis:Functional Insights to the Role of CaffeicAcid Phenethyl Ester and Its Complex With $\gamma$-Cyclodextrin, Integrative cancer therapies, 2018. doi.org/10.1177/153473541775354 